\title{
Occupational Health and Safety Issues in Militar Field Hospitals
}

\author{
MCM Bricknell
}

\begin{abstract}
This paper considers the occupational health and safety issues that apply within a military field hospital. It considers NHS occupational health and safety activities and examines how these might be applied within an Army Medical Services unit. Areas that are unique to field hospitals are highlighted in comparison with a static NHS hospital. Some issues for future work are also considered.
\end{abstract}

\section{Introduction}

This paper is part of a series that focuses on the practice of occupational health within the British Army. It will discuss occupational medicine, occupational health and health and safety issues as they apply within a deployable field hospital. The author is currently employed as a Commanding Officer of a field hospital and so the paper will concentrate on the issues as they affect the responsibility of the Commanding Officer rather than as they might affect an occupational physician. This paper will identify some areas where further work will improve concordance between the Army Medical Services (AMS) and NHS practice. It will make some proposals as to how this might be achieved.

A previous paper provided a detailed description of the organisation of field hospitals (1). In summary, Regular field hospitals have an in-barracks strength of approximately 100 personnel (cadre staff). The unit maintains its field equipment in barracks in order to be prepared for a military task. Once warned for deployment, the unit would be reinforced with clinical personnel to bring it up to the strength necessary to meet the size of field hospital required. The unit is organised into 3 basic building blocks: headquarters, clinical complex, support squadron and accommodation. The paper will discuss issues around personnel and these 3 building blocks.

\section{Issues}

\section{Personnel}

Readers of the Journal will be familiar with the well-rehearsed scheme to ensure that general occupational health issues are managed for Army personnel. This includes pre-employment medical examinations an periodic medical screening, routine and pr $\vec{\Phi}$ deployment immunisations and की occupational health overview of episodes $8 \mathrm{f}$ ill-health. Guidance on these matters $\vec{Q}$ contained in a variety of Joint Service and Army Publications. Interim policy is issu㻊 in the form of Surgeon General Poliag Letters or Director General Army Medic Services Policy Letters. The unit medicat officer should coordinate these activities foil cadre staff. Reinforcements should receive the same package of occupational healtio support from their local medical centre.

There are a number of occupational healttr issues specific to working in a clinic environment. Many NHS Trusts provide ag occupational health department for the? staff in order to meet this requiremen Military clinical staff should also receive specific occupational health support tailored to their needs as healthcare workers i addition to routine military occupation health activities. The Association of Nation Health Occupational Physicians (ANHOPS provides a forum for these occupation ${ }^{\circ}$ issues in the NHS. It is important tha occupational health support to militar healthcare staff meets similar standards.

Most NHS Trusts have a pre-employmen health screening process. In addition t⿳亠丷厂犬灬ं general health issues, the screening system likely to specifically assess musculoskeleta fitness for those involved in direct patien care (particularly the risk of low back problems) and psychological suitability. This second assessment is a result of recommendations from the Clothier Repor after the deaths of children in the care of Beverly Allit (2). All NHS Trusts are require@ to have a programme to manage the risks of transmission of blood-borne diseases (3)? This includes Hepatitis B immunisation an antibody testing. Other infectious diseases that have an implication for work in a clinica $\mathbb{P}$ environment include HIV, other types of vires hepatitis, rubella, tuberculosis, diptheriaç meningoccocal meningitis and methicillin $=0$ resistant staphlococcus aureus. It is important that the Defence Medical Service $\vec{\Phi}$ (DMS) provides standards for policy an $\frac{8}{8}$ delivery of occupational health surveillance for its healthcare workers similar to those juso described for the NHS. There may be scope for sharing the management of occupationa health issues for clinical staff with NHS? departments for those members (both
E-mail:

22fdhosp.101logbde@milnet.uk.net 
Regular and Territorial Army) of the DMS who work within NHS Trusts.

\section{Headquarters}

The headquarters environment in a deployed field hospital is essentially an office activity based in tents. The increasing use of IT resources, especially laptop computers, will require compliance with the Display Screen Equipment Regulations (4). This is a challenging task in view of the constraints of this working environment such as the need for folding chairs and tables, the limited flexibility of the field lighting system and the finite space available.

\section{Clinical Complex}

The clinical complex has a range of hazards that require specific management. The Department of Health has published comprehensive guidance on the management of the risk of hospital acquired infection (5). Policies for protection from blood-borne diseases and the management of infection control should be based on maintaining a clean working environment and frequent hand washing by clinical personnel. This, most basic of infection control practices, presents a significant challenge in the field hospital because of the problems associated with providing a clean water and waste water circuit. Innovative solutions such as hand wipes and alcohol based hand-cleansing solutions should be considered. Where there is a specific hazard, items of personal protective equipment may be used appropriate to the risk. It is now common practice to wear protective gloves for any procedure that is likely to involve handling patients' body fluids. If there is a significant risk of splatter from such material, protective gowns, aprons and eye protection should also be provided. The field hospital needs to ensure the same level of protection from handling medical 'sharps' and contaminated waste as would be expected in a civilian hospital. Personnel trained in infection control should be deployed with field hospitals in order to provide detailed advice on all of these issues.

Control of the risk of back problems arising from manual handling of patients is a major issue in civilian nursing practice to ensure compliance with the Manual Handling Operations Regulations (6). This is an even greater problem within field hospitals where the casualty flow is likely to be heavier than in NHS practice. Military stretchers are designed for utility and ease of storage and so do not have the built-in trolley systems often found in some civilian ambulances. Furthermore, the use of lifting aids may well be impractical due to the operating environment. The use of stretcher trolleys designed for military pattern stretchers is one way in which the risk of injury from patient handling has bees reduced.

Many hazards found in the civilian clinic environment can be directly transposed the military field hospital. The risks fro vapour hazards, for example, volatipe anaesethic agents and sterilising agents (e glutaraldehyde) need similar control systens based on enclosures to ensure complian $\overrightarrow{e_{2}^{2}}$ with the Control of Substances Hazardous to Health Regulations (7). The biologic워 hazards present in the laboratory and tof hazards from ionising radiation in the X-r@ department should also be controlled usirf conventional measures (8).

Support squadron and accommodation There are many aspects of the deployme and sustainment of a field hospital that age covered by Health and Safety legislation. The first issue is the size and volume of equipment. This is stored in lares warehouses and is transported to the site of operation in ISO containers. A number ơf packaging and lifting devices are used reduce the manual handling requireme $\vec{b}$ such as fork lift trucks and trolleys. TIR complete deployment sequence needs to the subject of a risk assessment and appropriate action taken to reduce the ris of injury.

A field hospital is a large, comple organisation that comprises a number of sursystems. These include: shelter system electrical circuits, water circuits, heating arof airconditioning circuits. Much of the equipment is managed by specially traing्⿹ technicians such as electricians and plumbers to ensure that it is installed accordance with the appropriate legislation, for example Electricity at Work Regulatio $(9,10)$. Non-specialist personnel need to briefed on the hazards and control measure associated with each system. The lare expanse of tentage represents a significant fire risk. The field hospital should have trained Fire Officer and ensure that plans age in place to evacuate the complex in the eve of a fire. The catering department shougd ensure that all catering practices conform food safety legislation. Finally, the motor transport section needs to ensure that vehicles are serviced and inspected, in accordance with the law, and that all drives comply with relevant regulations, especialy those concerning drivers hours. There may be scope to utilise the mechanisms f苂r managing drivers hours to manage wo: patterns for personnel working within the clinical complex.

\section{Discussion}

The Commanding Officer of a field hospital is responsible for all health and safety issuofs within the unit. The management of hear and safety is usually delegated to to Quartermaster and managed in accordance 
with Joint Service Publication 375, the Ministry of Defence Health and Safety Handbook. The Commanding Officer should ensure that a health and safety committee is established that reviews the health and safety issues across all aspects of the unit's activities as described in the previous section.

Many aspects of occupational medicine support to a field hospital are outside the control of the Commanding Officer. The medical aspects of the recruiting process for health care personnel within the Defence Medical Services should conform to NHS practice, for example, the review of psychological history. Unit medical centres should use their medical IT systems to ensure that the immunisation of health care personnel meets NHS standards. Commanding Officers need to be supported by a system of occupational health support to potential DSCA and TA reinforcements that ensures these personnel have been provided with the same level of occupational health support and screening as provided to NHS staff. This might be provided by generic regional services or a specific focus for occupational health standards for military health care workers. The procurement process for equipment for field hospitals should ensure that the units are provided with the proper equipment to meet health and safety legislation.

\section{Conclusions}

This paper has described the occupational health and health and safety issues that arise through the operation of field hospitats within the Army Medical Services. describes areas where NHS practice shou遍 be mirrored and challenges that are uniques to the military environment. It is ti responsibility of the Commanding Offic\&? of a field hospital to ensure that these issuo are addressed. There may be scope for increasing the linkage between the DMos and the NHS to ensure high qualig occupational health care is provided to bo Regular and Territorial Army personnot who work in NHS Trusts.

\section{References}

1. Organisation and design of Regular field hospitats Bricknell MCM. f Roy Army Med Corøू 2001;147:161-7.

2. Report of the Allitt inquiry. Department of Healt El (94) 16.

3. UK Health Departments Guidance for Clinich Health Care Workers: Protection Against Infection with Blood-borne Viruses Recommendations of the Expert Advisory Group on AIDS and the Advisory Group on Hepatitis. http:/www.opec gov.uk/doh/chcguidl.htm

4. Health and Safety (Display Screen Equipment? Regulations 1992 (SI 1992/2792).

5. Journal of Hospital Infection (200 47(Supplement): S5-S9 doi:10.1053/jhin.2000.0889. available online at http://www.idealibrary.com $\mathbb{D}$

6. Health and Safety (Manual Handling Operation Regulations 1992 (SI 1992/2793).

7. Health and Safety (Control of Substances Hazardous to Health) Regulations 1999 (D) 1999/3246)

8. The Ionising Radiations Regulations 1999 1999/3232)

9. Electricity at Work Regulations 1989 1989/635).

10. Electrical Equipment (Safety) Regulations 1998 (SI 1994/3260). 